some assistance in making a correct diagnosis. Blood is rarely found in gall-bladder cases. In ulcer it is present in one-fourth as against two-thirds of the cases of cancer of the stomach. Gastralgia is found in neurotic individuals, is relieved by pressure, and is not usually attended by nausea or vomiting. It is significant that a more thorough study of the pathology of lesions of the stomach and associated organs of digestion materially reduces the number of patients suffering with so-called gastralgia and other neuroses.

We might be called on to distinguish the girdle pain of locomotor ataxia from an attack of gall-stone colic. Here the Argyll-Robertson pupil, Romberg symptoms, loss of tendon reflex, and other signs of tabes would serve to differentiate.

Disturbance arising from the appendix, shown by gastric indigestion and pyloric spasm, are extremely diffieult of diagnosis from primary gall-stone disease, and the two troubles frequently co-exist.

There may be no tenderness over McBurney's point or any other of the usual signs of appendicitis except a type of continuous stomach trouble. In these cases, however, the history may show an attack of appendicitis. which was not treated at the time of its occurrence, and the patient is able to date his indigestion from this attaek. There is generally a loss of weight and considerable impairment of health. The effect of food on the pain is variable and the pain is usually in the neighborhood of the umbilicus. In appendical drspepsia, its continuous type is in marked contrast to the fleeting, irregular and sudden attacks of gall-bladder trouble, and to gastric ulcer, in which there is generally a definite relation between pain and the taking of food. Cannon, of Boston, has succeeded in producing erosion and ulceration of the stomach by the injection or irritants in the cecum. These experiments would seem to indicate that even organic trouble of the stomach may be produced by disturbance in the region of the ileocecal valve.

The only satisfactory treatment of gall-stones is their surgical removal. Occasionally patients recover after passage of the stone by ulceration through into the bowel or into the stomach, or the patient may go through life a chronic dyspeptic and die of some other disease. It is as much the mission of physicians and surgeons to relieve morbidity as to lower mortality, and though the relation between these two things is not always directly apparent, it nevertheless exists in every case. A patient with indefinite stomach trouble, such as is found in the early stage of gall-stone disease, is more susceptible to other diseases, even if the gall-bladder trouble never assumes a threatening attitude in itself.

The medical profession is practically going through now, in regard to gall-bladder disease, what they have already learned in regard to appendicitis. The modern physician does not think of waiting in appendicitis until an abscess has formed, but recommends that the appendix be removed as soon as it is known to be diseased. So in the case of gall-stones, instead of waiting until the patient has had the early stages and has begun to suffer from colicky pains, vomiting and jaundice, the gall-stones should be diagnosticated in the first stage when the irregular attacks of gastric disturbance, with the feeling of constriction and the formation of gas in the stomach, show that as yet there has been practically no organic change in the liver, gall-tracts, or pancreas. Removal of the stones at such a stage will almost certainly insure a return of the patient to perfect health. 421 West Grace Street

\section{VACCINATION AND SMALL-POX IN JAPAN}

S. KITASATO, M.D.

Director, Institute for Research in Infectious Diseases TOKYO, JAPAY

Since Jenner introduced the practical use of vaccination over a century ago, mankind in general has been well protected from the cruel onslaught of small-pox wherever the process is carried out. We are greatly surprised every now and then to find antivaccinationists among people far advanced in civilization like those of the United States of America. I should, however, never have attempted to make any criticism on their presumption, had not one of them, namely, Dr. Hodge, of Niagara Falls, referred to the facts gathered from our Japanese statistics in his paper in the Twenticth Century Magazine. I may be permitted, therefore, to try to make clear how vaccination is serving to wipe out small-pox in Japan.

\section{EPIDEMIOLOGIC OBSERVATIONS ON SMALL-POX AND ON PREVENTIVE MEASURES IN JAPAN}

The free communication between Japan, China and Corea in earlier days was the source which gave rise to great epidemics of small-pox quite frequently, until at last vaccination was introduced. Japanese history tells us that small-pox was imported for the first time into Kyushyu in the month of February, 123 B. C., after which it gradually spread toward the east as far as Kyoto, causing a great epidemic all. over the country, creating sad havoc, and strewing the high roads with the dead and dying. From this first great epidemic down to 1868, when the restoration of the present Meiji Era set in, about fifty epidemies broke out, each one of which extended over à number of years, sweeping all through the country, diminishing the population considerably and devastating the fertile country everywhere. Towards the end of the Tokugawa Shogunate the measure introduced by Jenner was adopted in Japan, with what favorable results we shall see below. During the ten years from the beginning of the Meiji Era-i. e., 1875-1884the number of patients suffering from small-pox averaged 2, (108.1 per hundred thousand population, while the deaths were only 494.6 , which was deemed to be a remarkable improvement.

One of the greatest epidemics of small-pox during the past forty years broke out in 1885 and lasted three years, with 125,315 cases and 31,960 deaths. The epidemic began to decline in 1888 . It reappeared in 1892 and again lasted three years. During this second outbreals 88,095 cases were recorded, of which 23,603 patients died. The third outbreak extended over two years, $1896-$ $189 \%$, with 52,650 cases and 15,664 deaths. During the next ten years, a few cases were imported from China every now and then, without any ensuing serious outbreak. Since 1900 , the cases in the whole empire were remarkably few, until in 190\%, when the disease reappeared at Kobe. This caused an uncommonly severe epidemic, which spread all through the empire. It began to die out in the spring of 1908. During this fourth epidemic 19,101 cases and 6,273 deaths were reported. This outbreak, however, completely subsided by July of the same year, without any trace left. The diagram inserted shows these epidemics most clearly.

Let us now turn our attention to what has been done to avoid the wretched results brought about by small-pox in Japan. In olden times when people were ignorant of what measures they should apply, they resorted to 
superstitious means to attempt to subdue the natural processes. One of the scientific measures, i. e., variolation, was introduced by a Chinese merchant, Lee-NinShan, in the year 1745. That often caused an outbreak of small-pox, and so many fell victims to it that people felt that they were doomed to suffer from small-pox once during their lifetime.

In 1849 , i. e., fifty-three years after Jenner had introduced vaccination, the process was first demonstrated in Japan by a Dutch physician, Monicke. The Japanese people were soon convinced of the marvelous effects of vaccination. Vaccinating stations were established in various great cities, e. g., Yeddo (now Tokyo), Kyoto and Osaka, in order to give the public the benefits of vaccination on a broader scale.

Japan, at that time, underwent a political change, and even medical science, which had begun to follow the teachings of the European school, was forbidden to continue by the Shogunate government. Vaccination was the only survivor of the newly introduced methods of the European school. This fact alone explains how far even the obstinate Japanese authorities were convinced of the efficacy of vaccination. The radical change lymph" was substituted. While humanized lymph was used, the original vaccine was supplied from the vaccinating stations. In 1874 the Japanese government established a calf-lymph farm, in order to meet the demands of the general public. In 1888 the preparation of ealf-lymph was entrusted to the Japan Health Association, which continued to prepare the lymph for eight years. During these years, other private institutions made their appearance which prepared calf-lymph for pecuniary considerations. The products of these private enterprises were unsatisfactory, for the efficacy of such lymph eventually became questionable and at last public opinion was aroused to establish a national institution for the preparation of calf-lymph, and in 1896 such an institution was established. In this institution Dr. Umeno tried the experiment of preparing a "pure animal lymph" by passing the vilus only through the calf, never using a human body as had been done previously. $\mathrm{He}$ succeeded in this experiment, and since 1900 this kind of calf-lymph has been supplied to the public. The original. calf-lymph farm was closed in the year 1906, and the calf-lymph is now prepared in the Institute for Research on Infectious Diseases.

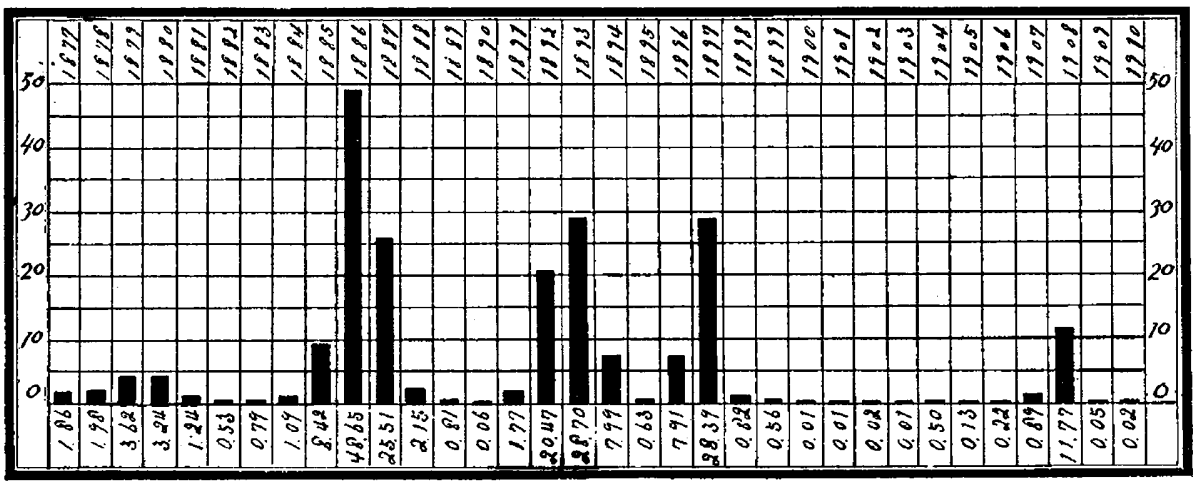

Diagram of small-pox mortality in Japan.

of government just forty-four years ago, which is known to history as the Restoration of the Meiji Era, brought about a completely new mode of politics, everything Occidental being introduced. In $\mathbf{1 8 7 4}$ the first vaccination law was enacted, and in $\mathbf{1 8 7 6}$ the regulations for the prevention of small-pox were promulgated, which provided for compulsory vaccination. In 1885 a revised law concerning vaccination was enacted. It comprised all the clata included in the former two regulations. It provided that every baby should be vaccinated within the first year of its age, and revaccinated every five or seven years. The violation of this regulation was punished with a fine not less than 5 and not exceeding 50 sen (or approximately, from $21 / 2$ to 25 cents in U. S. currency). It was in the same year, just after the enactment of these regulations, that the great epidemic broke out which is mentioned above. This regulation remained unchanged during twenty-four sears; a new revision took effect in the year 1909. This new law provides that each new-born baby shall be vaccinated within ninety days after birth and before June of the next year. Revaccination shall be made at the tenth year from birth (including the year in which the child was born). If either the primary or the secondary vaccination is unsuccessful, the child shall be revaccinated before December of the next year.

Formerly Japan, as well as every other country, used humanized lymph only. The retrovaccine was then used from 1892 till 1900 . In 1900 the present " $p$ ure animal
II. THE CAUSES OF THE EPIDEMICS OF SMALL-POX IN JAPAN

Ever since the promulgation of the first vaccination law in 1874 , and that of the second one in 187.6, when compulsory measures were first adopted, Japan has suffered from epidemics from time to time. The inefficacy of vaccination might therefore seem to be proved to shallow-minded observers, who do not fully realize the complicated nature of the origin of small-pox as well- as of other infectious diseases. These various causes should be thoroughly examined before the reliability of vaccination is questioned. Let us now, therefore, review the epidemiology of small-pox in Japan.

There seem to be at least five principal causes to account for the presence and continuance of small-pox:

1. The Importation of the Virus.-Tapan is surrounded by seas, beyond which lie several countries where preventive measures have never been taken. In these countries, small-pox exists continuously and at. every possible opportunity invades Japan. When we had only a limited means of communication some centuries ago, each epidemic could be traced back to importation of the virus from China through Corea, and in course of time the more the facilities of communication were augmented the more the country was found to be liable to infection. This compelled us to establish quarantine stations, which were opened in 1899. Since that date, and until the end of 1909 , the number of detected cases of small-pox at tliese stations amounted to seventy-one, as is shown in Table 1:

TABLE 1.-NIMPER OF CASES OF SMALL-POX DETECTED at QUARANTINE STA'TIONS DURING THE YEARS FROM 1899 TO 1909

\begin{tabular}{|c|c|c|c|c|c|c|c|c|c|c|c|}
\hline $\begin{array}{l}\text { Quarantine } \\
\text { Station }\end{array}$ & $\stackrel{\infty}{\infty}$ & $\stackrel{8}{\Xi}$ & 5 & I & 8 & \pm & 18 & $\stackrel{8}{\varrho}$ & 今 & 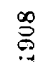 & $\stackrel{8}{\overparen{8}}$ \\
\hline $\begin{array}{l}\text { okohama } \\
\text { obe ...... }\end{array}$ & 1 & 1 & & & & 3 & 7 & & 1 & & $2-26$ \\
\hline & & 1 & & & & & 4 & & 1 & & $2-19$ \\
\hline & & & 2 & & & & & 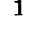 & & & -10 \\
\hline al... & & & & 1 & & & 12 & & 8 & 19 & -71 \\
\hline
\end{tabular}


These figures, of course, exclude by necessity those who passed the stations in the stage of incubation, which obviously made the prevention of the disease most difficult. The same difficulty is encountered in the most completely vaccinated country - Germany - which is bounded on one side by Russia, a non-vaccinated country. This is why there exist a few unavoidable cases of smallpox annually in that country. Imagine, then, how great is the chance of infection in Japan, which is in close proximity to China and Corea, whose condition of national health hardly admits even any comparison with that of Russia. This is one of the most conspicuous causative factors in the reappearance of small-pox in Japan. Japan is therefore never tired of preaching the gospel of vaccination, not only within her own dominions, but also as far as her sphere of influence permits.

Q. Non-Vaccinated People.-Laws cannot be expected to be all-powerful. Wherever there is a law, there are also to be met not a few law-breakers, even when the breach is met with severe penalties. It admits of no doubt that such laws as regulate matters of public health provide but slight penalties, and consequently there are not a few law-breakers among the ignorant mass of people. This fact will appear when we come to examine the figures given in our statistics, which equal nearly the whole population of the country. But the more minute particulars, which are not shown in the statistics, will clearly show the vague notion we have of the number of non-vaccinated individuals there are scattered throughout the country. Among the 10,600 persons with small-pox reported during the five years including 1878 1882 , non-vaccinated individuals were found to amount to 63 per cent., or 6,690 . Then again, during the latest epidemic, in the years $190 \%-1908,1,527$ non-vaccinated persons among 5,215 small-pox patients were found in one prefecture, i. e., in Hiogo.

Such law-breakers probably will be found in any nation where a vaccination law is enacted. The middle and higher classes of Japanese people never allow their children to go unvaccinated, but the lower classes, who constitute the majority of the nation, often neglect their duty. They are, like kerosene oil in a house where a fire breaks out, fuel for the flames, furnishing every possible chance for the spread of the disease. Under the revised vaccination law taking effect in the year 1909, the hitherto irresponsible protectors of children were subjected to penalties for failure to have them vaccinated.

3. Unsuccessful Vaccination.-The protection of the individual against small-pox is never complete unless the points of inoculation develop the typieal pustules, and the patient undergoes a regular symptomatic change. In order to bring about complete immunization in a human body, the quality of the vaccine lymph and the technic of vaccination must be considered.

In Japan, from the first year of the enactment of the vaccination law in 1887 up to $190 \%$, covering twenty-two years, the reported number of vaccinations was $97,355,-$ 246 , of which $73,259,278$ were compulsory and the remaining $24,355,968$ voluntary. The average number of vaccinations per year was more than $4,420,000$. Comparing this number with the whole Japanese population, there seems to be no one who has not been vaccinated; but a close examination of the real state of affairs will make clear the fact that in the above-mentioned large number of vaccinations are a certain number of unsuccessful vaccinations. Of course this large number of unsuccessfully vaccinated persons may also comprise some who have already acquired immunity by pre- vious vaccination. At the same time we must not overlook those who have been unsuccessfully vaccinated because of unskilful manipulation on the part of the physicians, who had practiced the puncturing system instead of the cutting method, even when the lymph had been changed for the retrovaccine and this again for the "pure animal lymph." The effect of this may be seen from the statistics, which show a great difference between the percentage of the primary vaccinations gathered from the eight years before 1891 and after 1892. In the first eight years when the humanized lymph had been used the percentage of successful vaccinations was high, ranging from 85 to 90 per cent., but in the later eight years when the retrovaccine was introduced the percentage fell suddenly to 75 or 80 . The figure, however, has been greatly increasing since 1900 , when it reached as high as 88 per cent.

In short, it must be acknowledged that vaccination in Japan is so irregular that while there are some who receive no vaccination until five or six years of age, others have been vaccinated three or more times during the same period of time, and the consequence is the comparatively less number of genuine vaccinations. This evil will be overcome by the adoption of the latest radical policy.

4. The Immunity Acquired Through Vaccination.Immunity through vaccination is not complete before three weeks after successful vaccination. This is why there are some cases of small-pox immediately following vaccination. Then again, the immunity is gradually weakened by the course of years. This fact may be seen from the following statistics:

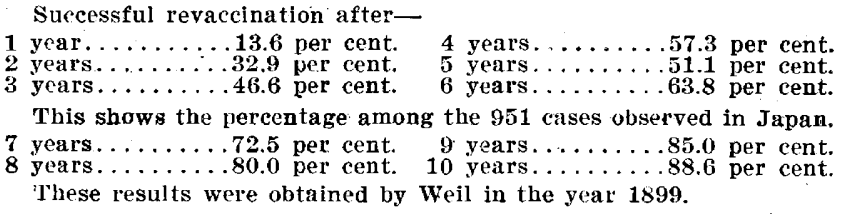

The government report of the German Confederacy shows 91 to 93 . per cent. of successful revaccinations after ten years from the primary. In other words, the immunity acquired through vaccination begins to disappear from the second year and by the tenth year it disappears almost completely. And therefore in Germany, and in some other countries, a law has been enacted to have the people revaccinated at the eleventh year from the primary vaccination.

The general statistics do not give these minute facts in detail, and therefore the deduction is imperfect. Had not the critics excluded these cases from the total revaccinated ones, they could not come to the conclusion which Dr. Hodge reached. For instance, during the latest epidemic in Japan, which broke out in 190\%-1908, 608 patients were admitted into the Higashiyama Hospital in Kobe; 267 of the number were non-vaccinated, the past history of thirty-eight was uncertain as to the vaccination, twenty-five had contracted the disease within three weeks after vaccination, four had had small-pox previously, nineteen contracted the disease within five year's and 225 over five years from the last vaccination. This show's also how far the immunity is impaired by the lapse of time.

5. Virulency of Small-Pox.-The virulency of smallpox is not constant in each epidemic. The higher the virulency of small-pox rises, the larger the number of cases among those who have passed several years from the last vaccination. Then, it may be asked, how can the virulency of snall-pox be estimated? The simplest 
way, it seems to me, is to estimate the death-rate among the non-vaccinated patients. The average death-rate of small-pox is estimated at from 20 to 40 per cent. in the European literature. In Japan, it shows a higher standard. ranging from 25 to 30 per cent. even during the fmall epidemics. During the epidemic of 1896-1897 it averaged 55.08 per cent., and that of the years $190 \%$ 1908 reached the high standard of 69.4 per cent. When the virulency reaches this high point, higher than has been encountered in European or American epidemics, even individuals previously attacked, as well as those vaccinated, contract the disease. During the latest epidemic, such cases were numbered at 242 in seven prefectures, viz., Hiogo, Osaka, Tokyo, Kanagawa, Hiroshima, Aichi and Wakayama, and fifty-seven died. The death-rate, therefore, was 23.5 per cent. This is unmistakable evidence of the strong virulency of the small-pox which prevailed at that time. It is like a devastating fire which consumes everything in its path and to which nothing is fire-proof. Japan dreads this kind of smallpox, which is also abetted by the other circumstances, but its direct results are by no means due to the inefficacy of vaccination.

\section{THE EFFICACY OF VACCINATION}

The efficacy of vaccination can be demonstrated by experiment, experience and statistics.

1. The fact that vaccinated individuals do not contract small-pox was made clear by Woodylle, William and others immediately after Jenner's experiment, by inoculating the virus of small-pox into the vaccinated individual. In modern times the same experiment has been made, of course for different purposes, with monkeys. Brinkerhoff and Magrath before the year 1904, and Dr. Miyajima, one of my assistants, in 1908 vaccinated a large number of monkeys with calf-lymph. and then inoculated them with the virus of small-pox, but none of the experimental animals contracted the disease. This is an established fact in science, and there is none who can deny it.

2. Empirical testimony can be best drawn from the great epidemics, in which a great many persons engage in transporting, nursing, inspecting and disposing of both the sick and the dead without the least apprehension, because every one of them has received a thorough vaccination. In Japan, those who engage in this kind of work are vaccinated regularly within a certain period of time, and the consequence has been that none of them fell a victim to the pestilence. If, on the contrary, they had never been vaccinated, the result would be nothing but disastrous. If vaccination had no preventive effect on small-pox, they would have fallen victims before anybody else. If, then, the results had occurred just the reverse to the real state of things as claimed by the Jennerists, they should have abandoned their claims a long time ago. But the general public outside the profession is well convinced of the efficacy of vaccination simply because of this empirical testimony, which constitutes an indisputable fact.

3. Statistical facts also bear witness to the efficacy of vaccination. But tables and diagrams shown in statistics do not explain themselves. The most minute and scrupulous examination as to the hidden meaning of them, which only can breathe into the dry framework of figures the spirit of truth, is necessary, so that fallacy may be avoided. In almost every civilized country where there is a perfect system of vaccination in vogue, there occur no great epidemics of sniall-pox, and consequently the death-rate among them is very low. If an epidemic should occur, it would soon yield to vaccination.

Unfortunately, in Japan we are still having occasional epidemics of small-pox, which constitute for certain fanatic superficial observers a sad example of the inefficacy of vaccination. We have ample reason to believe, however, that the very things which Dr. Hodge and other antivaccinationists hold as evidence against Jennerism are the solid rocks on which the statistical proof of the efficacy of vaccination rests.

In the first place, in proportion as the system of vaccination had been perfected, the period of each epidemic and the number of deaths are diminished. This fact may be seen from Table 2 :

TABLE 2.-NUMBER OF CASES, DEATHS AND DEATH-RATE PER HUNDRED IN VARIOUS EPIDEMICS

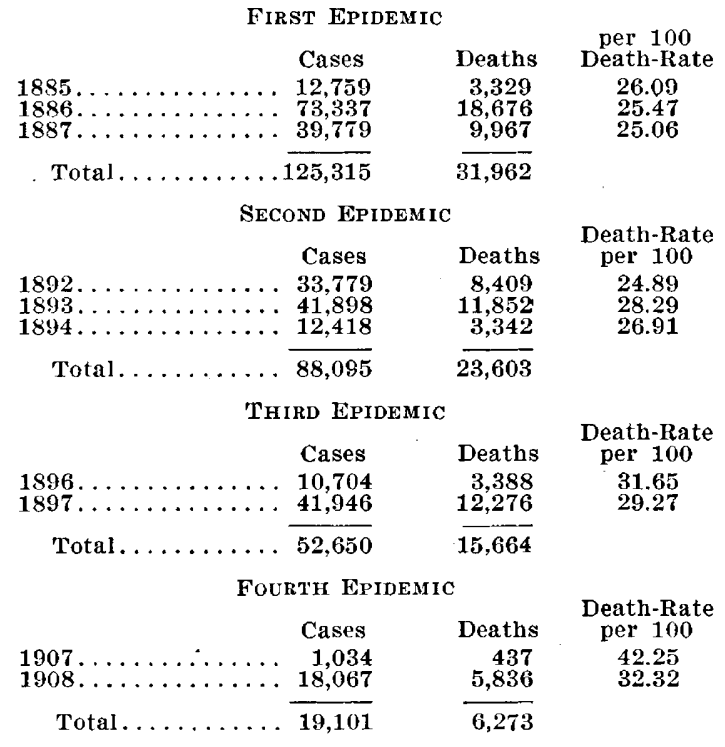

The first and the second epidemics each lasted fully three years, and the third two years, while the fourth broke out in December, 190\%, and ceased completely in August of the following year, covering a period of less than a year. The number of cases again shows a gradual decrease. While the first epidemic had over 100,000 cases, the second had 80,000 and the third 50,000, the fourth had less than 20,000 .

The marvelous effect of vaccination on the epidemics of small-pox is manifested in Table 3, which shows the sudden fall in new cases during the epidemic, which otherwise would have increased. The table does not show the long list of the vaccinated persons, but from the beginning of the epidemic down to the close a special vaccination was enforced on all persons who were brought under the control of the hygienic police power.

TABLE 3.-MONTHLY REPORT OF SMALLPOX DURING THE YEARS 1907 AND 1908

\begin{tabular}{|c|c|c|c|}
\hline & Cases & & Deatl \\
\hline August, 1907 .. & 4 & & 2 \\
\hline eptember, $1907 \ldots \ldots \ldots \ldots$ & 1 & & \\
\hline October, 1907 .. & 25 & & \\
\hline November, 1907 & 90 & & 31 \\
\hline December, 1907 & 770 & & 383 \\
\hline January, 1908 & 4,481 & & 1,394 \\
\hline February, 1908 & 5,424 & & 1,498 \\
\hline March, $1908 \ldots$ & $.4,685$ & & 1,461 \\
\hline April, 1908 & $.1,815$ & & 895 \\
\hline [ay, 1908 & 926 & & 314 \\
\hline e, 190 & 526 & & 185 \\
\hline 19 & 121 & & $7:$ \\
\hline st, & 36 & & \\
\hline
\end{tabular}

During this epidemic a striking effect of vaccination in mitigating the virulency of small-pox was experienced. 
While it prevailed in Hiogo and Osaka, special compulsory vaccination was enforced, and consequently in Kanagawa, Tokyo, Aichi and Kyoto it prevailed less furiously, as is shown in Table 4 :

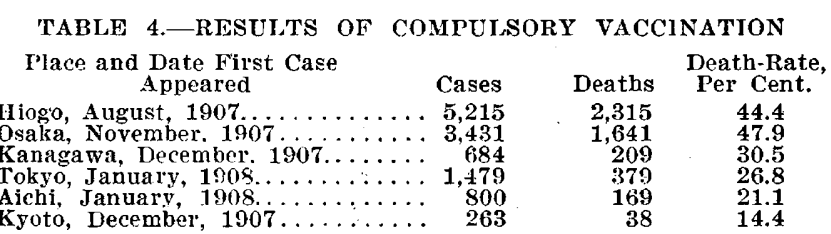

The drop in the figures in cases and deaths conld never have been so great had it not been for the effect of vaccination.

6. The death-rate in small-pox is given as about 30 per cent. by authorities, but it shows a wide range of figures in various epidemics, just as we see in any other infectious disease. Again, the comparison between the death-rate of small-pox among vaccinated persons and non-vaccinated ones cannot be established unless the data be collected from only one locality in the course of one epidemic. In Japan we have rare statistics which show such comparison. They cover five years from 1878 to 1882 . The total number of cases during that time amounted to 10,600 , of which number the following figures are given:

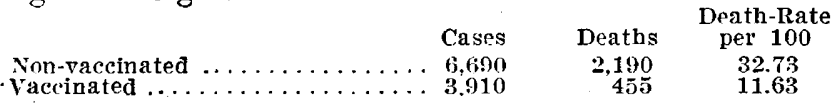

From the above figures it will be seen that the mortality among the vaccinated persons was not more than one-third of that among the non-vaccinated.

The following figures show the same conditions, where clear distinction could be made between the vaccinated and non-vaccinated, in Tokyo, Kyoto, Osaka, Hiogo, Kanagawa and Aichi, where during the latest epidemic the cases numbered 10,286 :

\begin{tabular}{|c|c|c|c|}
\hline & Case & Deaths & $\begin{array}{c}\text { Death-Rate } \\
\text { per luv }\end{array}$ \\
\hline Non-vaccinate & $\frac{2}{7}, 932$ & 2,031 & 69.3 \\
\hline
\end{tabular}

The above figures show the decrease in the death-rate among the vaccinated persons to one-half that of the non-vaccinated ones.

The vaccinated persons in the above table include those who were vaccinated within three weeks from the time of exposure and those who had passed the time assigned as the infective period. If these cases be deducted from the number the result would be more accurate.

During the epidemic of 1907-1908, the first case appeared in Kobe City and the disease prevailed most severely there. The Higashiyama Hospital at Kobe admitted 608 patients in all, who may be classified as in Table 5:

\section{TABIE 5.-CASES IN HIGASHIYAMA HOSPITAL}

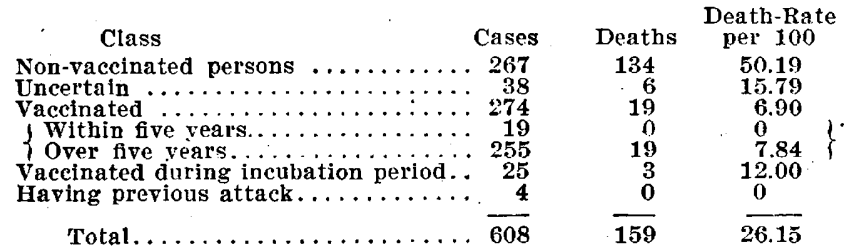

From this table it will be clear that the death-rate among the non-vaccinated persons was 50 per cent., while that of the vaccinated was 6.44 per cent., i. e., one-seventh that among the non-vaccinated. Again, all the deaths among the vaccinated persons occurred exclusively among those who had passed over five years from the last vaccination and among those who had been vaccinated during the incubation period. No one will doubt the efficacy of our Japanese vaccination, now that such a clear table of statistics is produced. Besides, the table shows that even among those who were vaceinated during the incubation period, the death-rate was four times smaller than that of the non-vaccinated ones.

$\%$. There is, besides the above statistics, the following circumstance which constitutes still another strong piece of evidence. I refer to the statistics of our army during the two great wars, the Chino-Japanese and the RussoJapanese. Our army engaged in both wars in Corea and Manchuria, where small-pox is endemic, and therefore the soldiers were constantly exposed to the danger of contamination; the more so when the unhealthy way of living which is a necessary concomitant of war is taken into account. However, the Japanese authorities took care to have every soldier who went to the seat of war vaccinated, and the happy result was that in an army consisting of not less than a million of men, the following small number of cases of small-pox appeared:

Chino-Jap. war : 155 cases; 34 deaths; death-rate, 21.93 per cent. Russo-Jap. war: 362 cases; 35 deaths; death-rate, 9.66 per cent.

As the total number of men engaged in both wars is not yet made known, the rate of contamination and the death-rate cannot be accurately stated; however, we get from these approximate figures some notion as to the paucity of cases. The results are equal to, if not better than, those of the Prussian army during the war of $\mathbf{1 8 7 0}$.

\section{CONCIUSION}

Japan is surrounded by non-vaccinated countries, whence contagion may flow in at any time, while the ignorant people do not care to receive vaceination; those who neglect it are therefore predisposed to be infected at the slightest chance. The enormous number of vaccinated individuals which appears in our statistics does not include all the people who should be vaccinated, but it does include a large number of persons revaccinated at an earlier time than the law of immunity requires, because they are well aware of the efficacy of vaccination as well as very anxious to protect themselves from the dangerous contagion.

From these various causes, there still prevail epidemies of small-pox in Japan. I regret that these statistics presented by our Japanese government have seemed to afford data for upholding the theory of the antivaccinationists in America. Every civilized individual of Japan knows the benefit of the marvelous discovery of Jenner, because he sees from time to time how he himself and his neighbors are protected from horrible epidemics. It seems to me that the presence of such an antivaccinationist as Dr. Hodge, who denies the efficacy of vaccination so frankly in the United States of America, is a striking witness to the fact that the people of America are already well protected by not having had the sad experience of an -attack of small-pox for a long time, and by the fact that their neighbors are being thoroughly raccinated. The antivaccinationists are like those who would deny the benefit of sunshine. It gives them every kind of joy and happiness, and yet they are so familiar with. it that they are not aware of its good. They would come to know the vast protective power of vaccination, had they once experienced the terrible outbreaks of small-pox in their communities, in which thousands on thousands fall victims while the vaccinated ones go freely through. the epidemic without the least danger of contagion. 